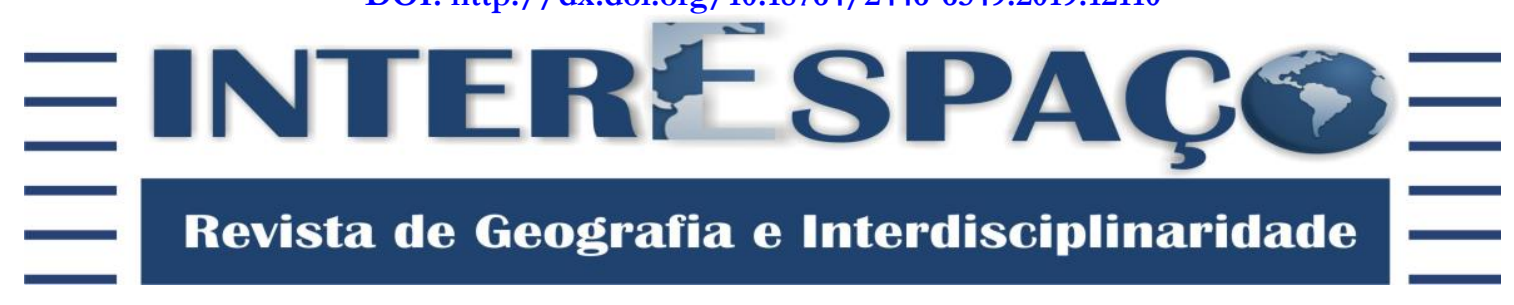

\title{
GEOTURISMO NO NATURAL BRIDGE CAVERNS, TEXAS, ESTADOS UNIDOS DA AMÉRICA
}

\author{
GEOTURISM AT THE NATURAL BRIDGE CAVERNS, TEXAS, USA
}

\section{EL GEOTURISMO EM LO NATURAL BRIDGE CAVERNS, ESTADO DE TEXAS, ESTADOS UNIDOS}

\begin{abstract}
Claudio Silva Porto
Doutor em Geografia - Tratamento da Informação Espacial pela Pontifícia Universidade Católica de Minas Gerais - PUC Minas. Professor do Curso de Educação Física do Centro Universitário de Caratinga - UNEC. claudiosporto@yahoo.com.br

\section{Luiz Eduardo Panisset Travassos}

Doutor em Geografia - Tratamento da Informação Espacial pela Pontifícia Universidade Católica de Minas Gerais - PUC Minas. Doutor em Carstologia pela Universidade de Nova Gorica, Eslovênia. Professor do Programa de Pós-Graduação em Geografia - Tratamento da Informação Espacial da PUC Minas. luizepanisset@gmail.com / http://orcid.org/0000-0001-6264-2429
\end{abstract}

Recebido para avaliação em 19/08/2019; Aprovado para publicação em 15/11/2019.

\section{RESUMO}

Nos últimos anos, vêm-se aumentando o número novas propostas de prevenção à degradação do meio ambiente, com o objetivo de conservar os recursos naturais, como forma de suporte à vida na Terra. O geoturismo pode ser considerado um instrumento pertinente na valorização e divulgação da geodiversidade, bem como da conservação do patrimônio geológico. O presente estudo teve como objetivo mostrar a utilização do geoturismo do Natural Bridge Caverns, no Estado do Texas USA. A pesquisa foi realizada através de estudo de campo, com a observação e registro fotográfico das atividades geoturísticas oferecidas aos visitantes, bem como a observação e registro fotográfico da infraestrutura para a recepção dos visitantes. O Natural Brigde Caverns é um parque que possui uma grande área, que é muito bem explorada. Com várias atrações e atividades ao ar livre para os turistas, consegue despertar o interesse das pessoas de todas as idades, fazendo com que os visitantes aproveitem todo o dia no parque. Desde a chegada ao parque, o turista é conscientizado sobre a importância da preservação da natureza e de da interação homem-meio ambiente. $O$ sistema organizacional do Natural Bridge Caverns pode servir de modelo para parques brasileiros que possuem cavernas, para que utilizem todo o seu potencial geoturístico de forma sustentável, gerando receitas e colocando os visitantes perto das belezas naturais do Brasil.

Palavras-chave: Geoturismo; Cavernas; Meio Ambiente.

\section{ABSTRACT}

In recent years, the number of new proposals for the prevention of environmental degradation has been increasing, aiming to conserve natural resources, as a way of supporting life on earth. Geotourism can be considered a relevant instrument in the appreciation and dissemination of geodiversity, as well as the conservation of geological heritage. The present study aimed to show the use of geotourism in Natural Bridge Caverns, in the State of Texas - USA. The research was carried out through a field study, with the observation and photographic record of the geotourism activities 
| Claudio Silva Porto | Luiz Eduardo Panisset Travassos |

offered to the visitors, as well as the observation and photographic registration of the infrastructure for the reception of the visitors. The Natural Bridge Caverns is a park that has a large area, which is very well explored. With many attractions and outdoor activities for tourists, it catches the interest of people of all ages, making visitors enjoy all day in the park. From the arrival in the park, the tourist is made aware of the importance of the preservation of nature and the human-environment interaction. The Natural Bridge Caverns organisational system can serve as a model for Brazilian parks that have caves that utilise its geotouristic potential in a sustainable way, generating revenues and placing visitors close to Brazil's natural beauties.

Keywords: Geotourism; Caves; Environment.

\section{RESUMEN}

En los últimos años, el número de nuevas propuestas para la prevención de la degradación ambiental ha ido en aumento, con el objetivo de conservar los recursos naturales, como una forma de apoyar la vida en la tierra. El geoturismo puede considerarse un instrumento relevante en la apreciación y difusión de la geodiversidad, así como en la conservación del patrimonio geológico. Este estudio tuvo como objetivo mostrar el uso del geoturismo en Natural Bridge Caverns, en el estado de Texas, EE. UU. La investigación se realizó a través de un estudio de campo, con la observación y el registro fotográfico de las actividades geoturísticas ofrecidas a los visitantes, así como la observación y el registro fotográfico de la infraestructura para la recepción de visitantes. Natural Brigde Caverns es un parque que tiene una gran área, que está muy bien explorada. Con numerosas atracciones y actividades al aire libre para turistas, puede despertar el interés de personas de todas las edades, haciendo que los visitantes disfruten todo el día en el parque. Desde su llegada al parque, los turistas son conscientes de la importancia de la preservación de la naturaleza y la interacción humano-ambiental. El sistema organizativo de Natural Bridge Caverns puede servir como modelo para los parques de cuevas brasileños que utilizan todo su potencial de geoturismo de manera sostenible, generando ingresos y acercando a los visitantes a la belleza natural de Brasil.

Palabra clave: Geoturismo; Cuevas; Ambiente.

\section{INTRODUÇÃO}

Nos últimos anos, vêm-se aumentando o número novas propostas de prevenção à degradação do meio ambiente, com o objetivo de conservar os recursos naturais, como forma de suporte a vida na terra.

Conforme Mantenesso Neto (2010), a apreciação da natureza, por si, é coisa antiga; praticamente desde que temos registros escritos, podemos encontrar menções elogiosas ao meio natural que vão além da mera visão utilitária. O que parece, porém, é que praticamente não se encontra a vinculação dessa beleza a conceitos geológicos - mesmo porque estes só começaram a se cristalizar como tal ao redor da passagem do século XVIII para o século XIX.

Borges, Travassos e Guimarães (2013) constataram a importância de se criarem mecanismos que estimulem a conservação do patrimônio geológico como, por exemplo, a implantação de um sistema turístico capaz de cumprir essa tarefa por meio da sensibilização ambiental de seus visitantes, com o objetivo da geoconservação da geodiversidade. 
Geoturismo consiste na disponibilização de serviços e meios interpretativos que promovem o valor e o benefício social de geossítios geológicos e geomorfológicos, assegurando simultaneamente a sua conservação para uso de estudantes e turistas (HOSE, 2000 apud UFSC, 2014).

Assim, o geoturismo é um turismo sustentável com foco primário na experiência da Terra e suas características geológicas, de uma forma que promova a compreensão ambiental e cultural, apreciação e conservação, e é localmente benéfico. Trata-se de criar no geoturismo um produto que protege o patrimônio geográfico, ajuda a construir comunidades, se comunica e promove herança geológica e trabalha com uma grande variedade de pessoas diferentes. A geologia é o estudo da Terra, enquanto a geomorfologia é o estudo das formas de relevo. Recursos naturais incluem paisagens, formas de relevo, afloramentos de rocha, tipos de rocha, sedimentos, solos e cristais. A parte "turismo" significa visitar, aprender e apreciar. Em geral, o geoturismo compreende os elementos geológicos de 'forma' e 'processo' combinados com o componente do turismo, como atrações, acomodação, passeios, atividades, interpretação, bem como planejamento e gerenciamento (DOWLING, 2013).

Segundo a Declaração de Arouca (UNESCO, 2011), o geoturismo é o turismo que sustenta e incrementa a identidade de um território, considerando a sua geologia, ambiente, cultura, valores estéticos, patrimônio e o bem-estar dos seus residentes. Nesta definição, o turismo geológico aparece como um dos diversos componentes do geoturismo (UFSC, 2014).

O geoturismo pode ainda ser descrito como tendo uma série de características essenciais. Esses elementos se combinam para moldar o geoturismo em sua forma atual. Compreende um número de componentes inter-relacionados, todos os quais devem estar presentes para o geoturismo autêntico ocorrer. Existem três princípios fundamentais que são fundamentais para o geoturismo. Eles são que o geoturismo é baseado geologicamente (isto é, baseado na geoherança da Terra); sustentável (isto é, economicamente viável, reforçando a comunidade e promove a geoconservação); e educativo (alcançado através de geointerpretação). As três características são consideradas essenciais para um produto ser considerado um exemplo de geoturismo (DOWLING, 2013).

Por não possuírem maiores ou nenhum conhecimento sobre geologia e geomorfologia muitos turistas veem os elementos da geodiversidade como um componente estático da paisagem, contudo a atividade geoturística busca não apenas a apreciação destes elementos pelo turista, mas também a compreensão das formas e processos que atuaram sobre eles, dando-lhes as formas atuais (LOPES; ARAUJO; CASTRO, 2011). 
Bento e Rodrigues (2010) afirmam que o geoturismo pode de fato ser considerado um instrumento pertinente na valorização e divulgação da geodiversidade, bem como da conservação do patrimônio geológico. Além disso, geoturismo e geoconservação podem também ser tomados como indutores do desenvolvimento econômico local, propiciando a gestão e utilização do patrimônio geológico, de forma planejada e sustentável.

De acordo com Evangelista e Travassos (2015), os itinerários geoturísticos surgem como uma proposta de disseminação do conhecimento científico, valorização e conservação do patrimônio geomorfológico enquanto patrimônio natural vulnerável à ação antrópica. Aliado aos itinerários tem-se o incentivo à prática de atividades ao ar livre, bastante usual nos dias de hoje.

O presente estudo teve como objetivo descrever o funcionamento e as atividades geoturísticas do Natural Bridge Caverns. Farsani et al. (2011) citado por Jorge e Guerra (2016) veem no geoturismo rural uma estratégia para o desenvolvimento econômico de áreas rurais através dos geoparques, considerado uma inovação e proteção dos recursos naturais e patrimônios geológicos. Os geoparques são vistos como uma possibilidade de geração de emprego ao estimular a produção local, como exemplo: o artesanato, as atividades culturais, a observação de aves, entre outros. Esta nova visão do geoturismo e geoparques pode criar novos produtos, novos postos de trabalho e novas atividades recreativas.

\section{ASPECTOS METODOLÓGICOS}

A pesquisa foi realizada através de estudo de campo, com visita técnica e a observação e registro fotográfico das atividades geoturísticas oferecidas aos visitantes, bem como a observação e registro fotográfico da infraestrutura para a recepção dos visitantes.

\section{Área de Estudo}

A área do Natural Bridge Caverns está localizada a 30 minutos ao norte de downtown San Antônio e a 8 milhas oeste, na saída 175 da rodovia I-35 (Figura 1). 
Figura 1 - Entrada do Natural Bridge Caverns.

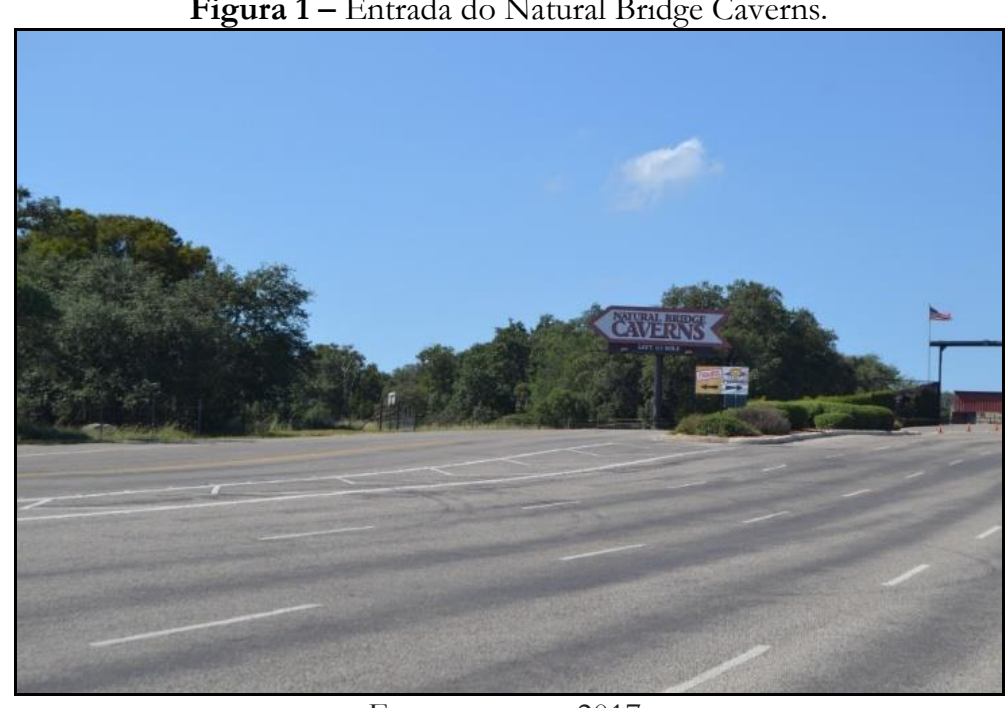

Fonte: o autor, 2017

Natural Bridge Caverns é a caverna mais extensa dentro da área de San Antonio e uma das maiores cavernas do estado do Texas. O Natural Bridge Caverns foi descoberto no ano de 1960, quando quatro estudantes universitários da St. Mary's University, em San Antonio, obtiveram permissão dos proprietários para explorar a área. Os exploradores percorreram o primeiro caminho, entrando sob a ponte de pedra calcária, rastejando e escalando através de duas milhas, de passagens vastas.

Lanças de indios pré-historicos, datadas de 5000 anos antes de Cristo foram encontradas, bem como ossos do maxilar de um urso-cinzento, um osso da perna de um índio e pontas de lanças datadas de 8 mil anos foram encontradas durante a exploração das cavernas (OFFICIAL TEXAS HISTORICAL MARKER, 1967).

As cavernas foram abertas para a visitação em 3 de julho de 1964. Pessoas de todo os Estados Unidos, Mexico, Canadá e muitos outros países visitam anualmente as cavernas.

\section{ATIVIDADES GEOTURÍSTICAS}

A primeira atividade do dia oferecida pelo parque é chamada de "Lantern Tour", na qual os turistas percorrem e exploram a caverna utilizando apenas suas lanternas. Sempre com um guia do parque, o objetivo dessa caminhada é fazer com que os turistas façam o mesmo caminho que os descobridores fizeram e se sintam como os primeiros exploradores nas passagens e salões do Natural Bridge Caverns. Nesta caminhada, os turistas percorrem 1,2 km e chegam à profundidade de 54,86 m, no tempo estimado de 75 minutos. 
| Geoturismo no Natural Bridge Caverns, Texas, Estados Unidos da América|

| Claudio Silva Porto | Luiz Eduardo Panisset Travassos |

O passeio mais popular na caverna é chamado de "Discovery Tour". A partir da entrada da ponte de pedra (Figuras 2 e 3) o turista percorre a caverna com total segurança, acompanhado e ouvindo o guia turistico durante todo o trajeto (conforme Figura 4).

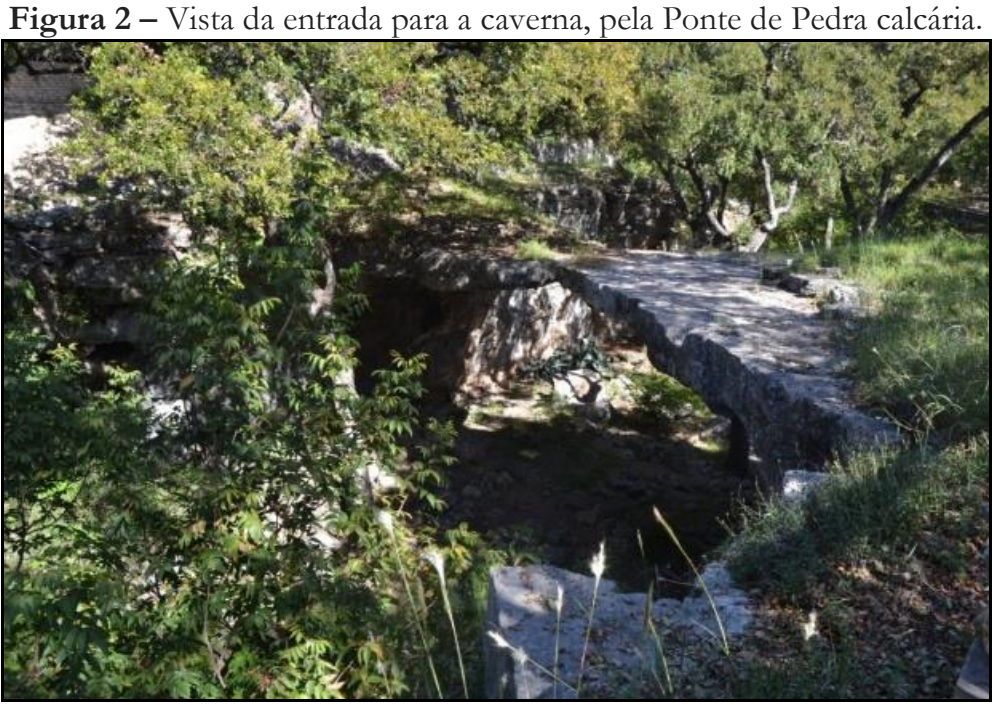

Fonte: o autor, 2017.

Figura 3 - Vista da entrada para a caverna.

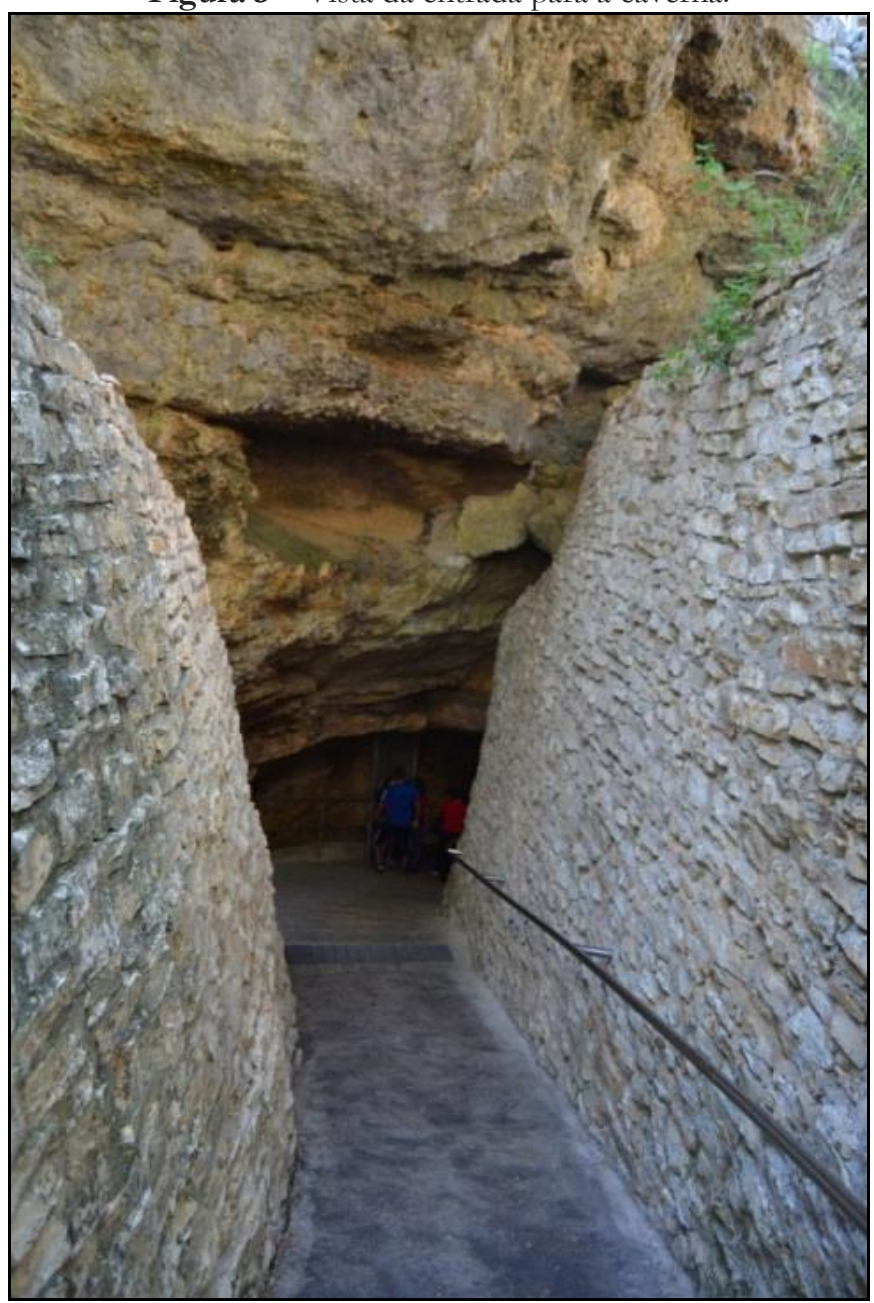

Fonte: o autor, 2017. 


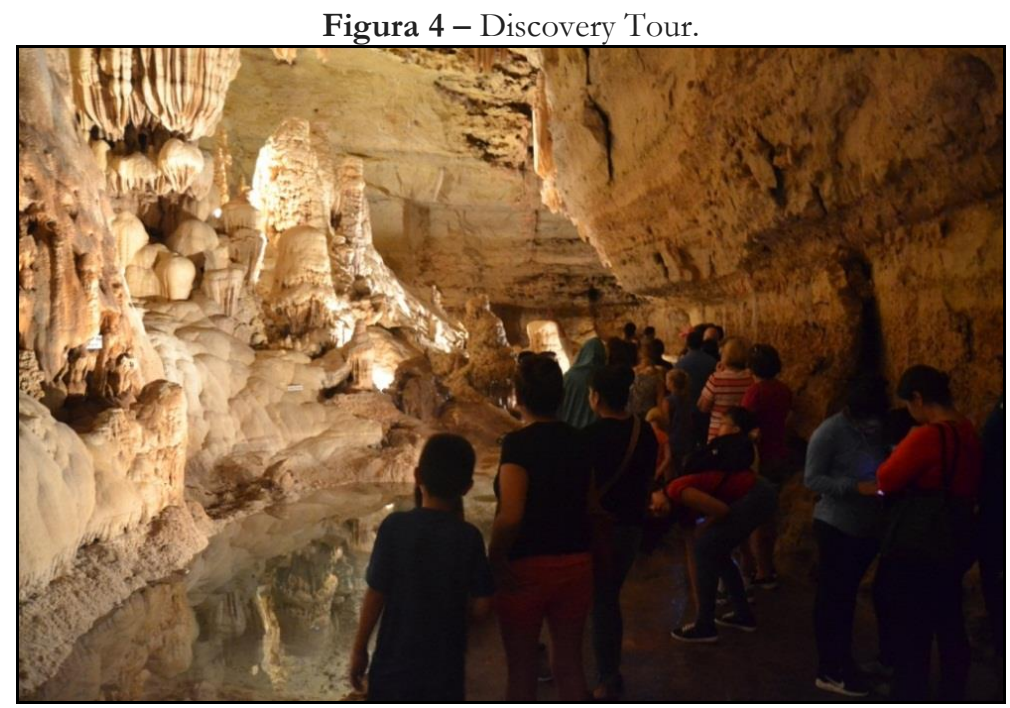

Fonte: o autor, 2017.

Outra atividade proposta pelo Parque é o "Hidden Passage Tour", onde os turistas terão a oportunidade de explorar as câmaras subterrâneas através de passagens escondidas, decoradas com algumas das formações mais raras e delicadas (Figura 5).

Figura 5: Hidden Passage Tour.

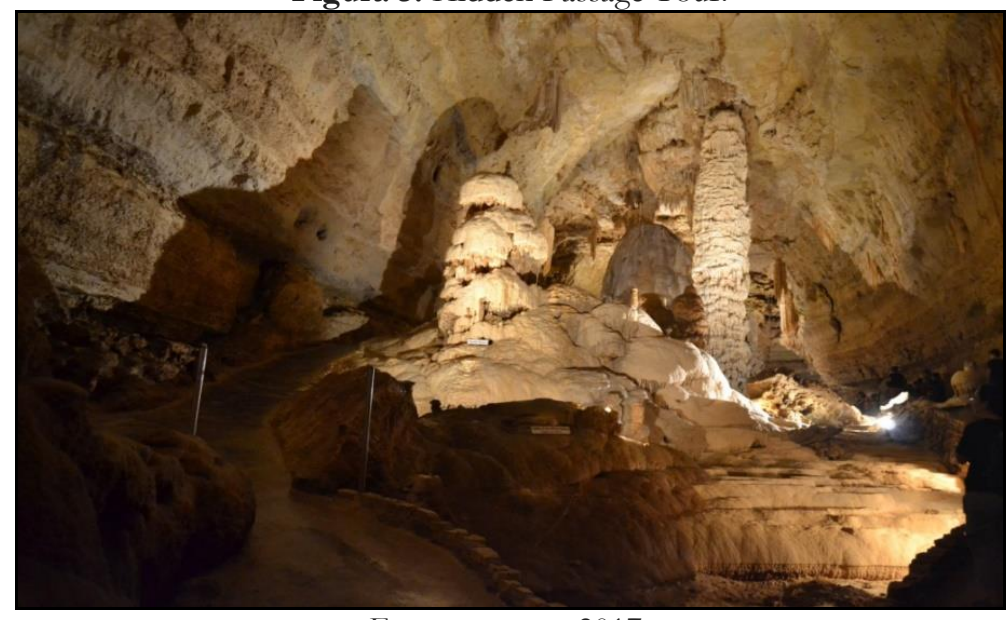

Fonte: o autor, 2017.

Nesta caminhada, os turistas percorrem os mesmos $1,2 \mathrm{~km}$ e chegam à profundidade de $54,86 \mathrm{~m}$, no tempo estimado de 75 minutos, mas com o local todo ilumidado, de forma que possam apreciar as exuberantes estalagmites, estalactites, flores, candelabros, soda straws e o rio que percorre o local.

O Canopy Explorer Course \& Canopy Zip Lines são atrações do Natural Bridge Caverns para adultos e crianças testarem o equilíbrio, agilidade e força em curso de 47 obstáculos de quatro andares, chegando a 20 metros de altura. Nessas atrações, os visitantes se divertem e deslumbram a paisagem do Parque (Figura 6). 
| Geoturismo no Natural Bridge Caverns, Texas, Estados Unidos da América|

| Claudio Silva Porto | Luiz Eduardo Panisset Travassos |

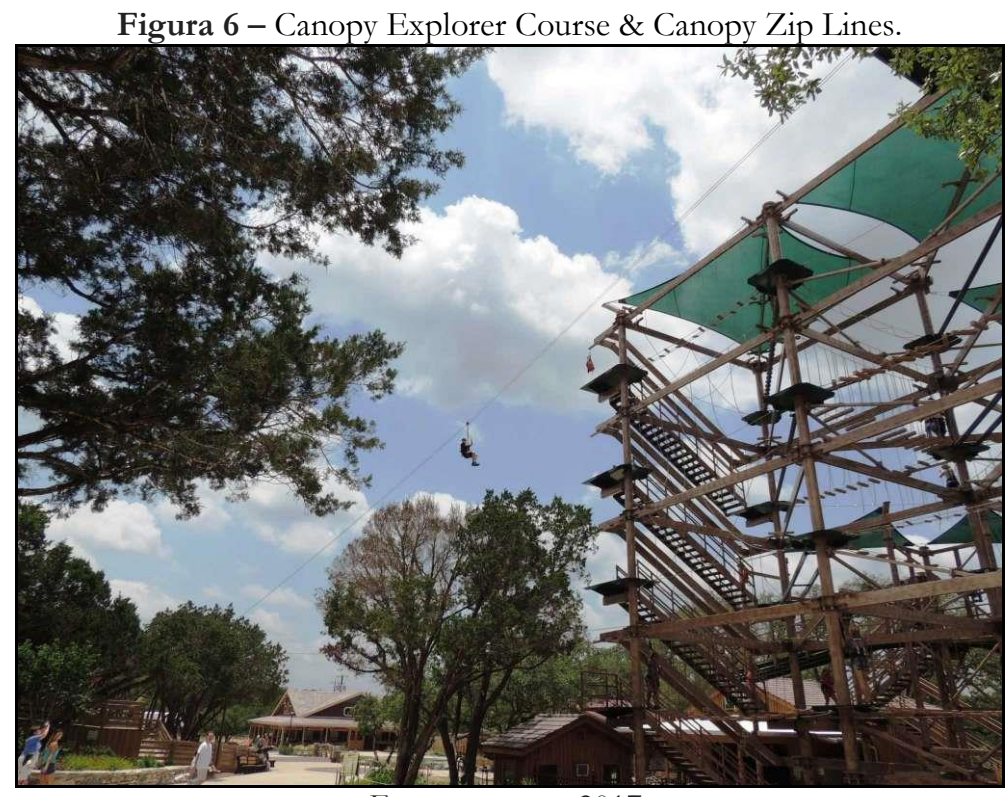

Fonte: o autor, 2017.

O Natural Brigde Caverns também oferece ao turista o Brake Bat Flight, que é a oportunidade de assistir a revoada de milhões de morcegos, que saem da Brake Cave para caçar insetos (Figura 7).

Figura 7 - Revoada de morcegos.

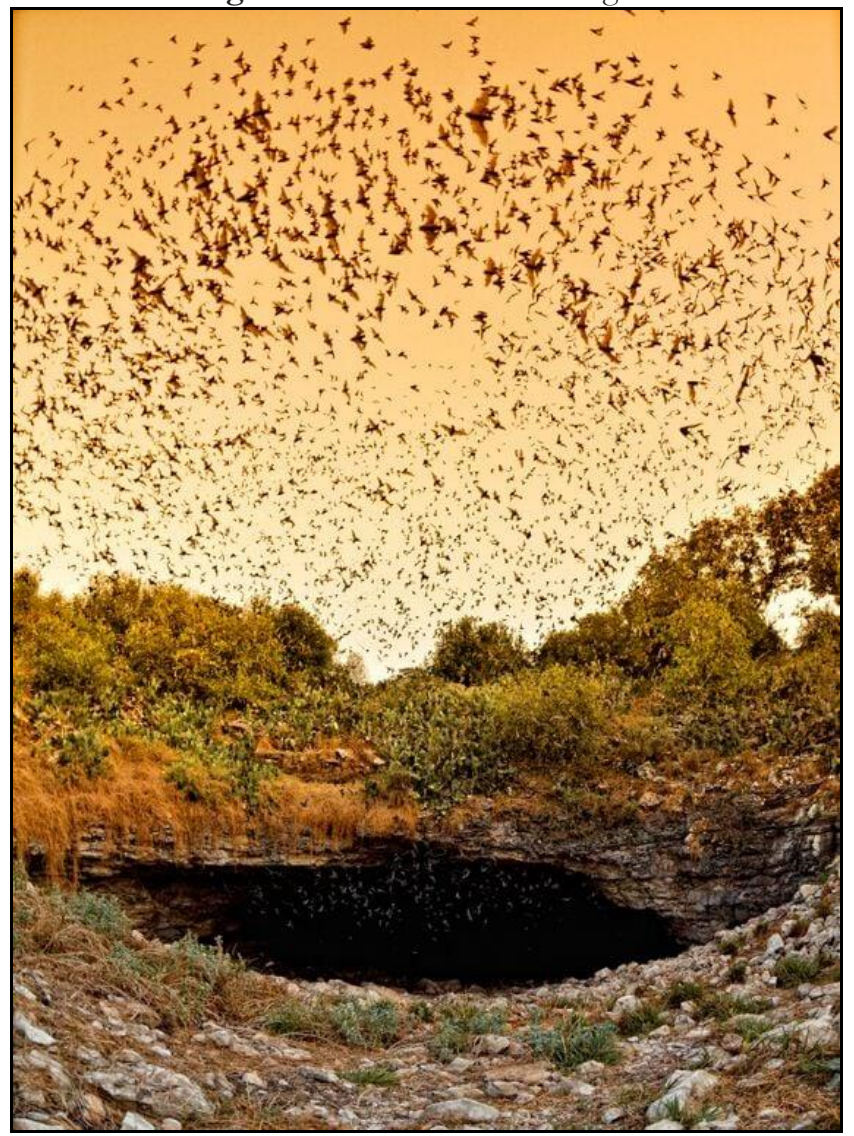

Fonte: Natural Bridge Caverns, 2018. 
| Geoturismo no Natural Bridge Caverns, Texas, Estados Unidos da América|

| Claudio Silva Porto | Luiz Eduardo Panisset Travassos |

\section{INFRAESTRUTURA PARA O VISITANTE}

O Natural Bridge Caverns possui um amplo estacionamento (gratuito) para os visitantes. Dentro do Parque, o prédio principal possui amplo espaço, com recepção, restaurante e lanchonete, loja para venda de souveniers e pedras, banheiros limpos, áreas adaptadas para deficientes físicos, espaço coberto para descansar (Figura 8). A segurança do local é outro ponto importante, assim como acontece em todos os locais no estado do Texas.

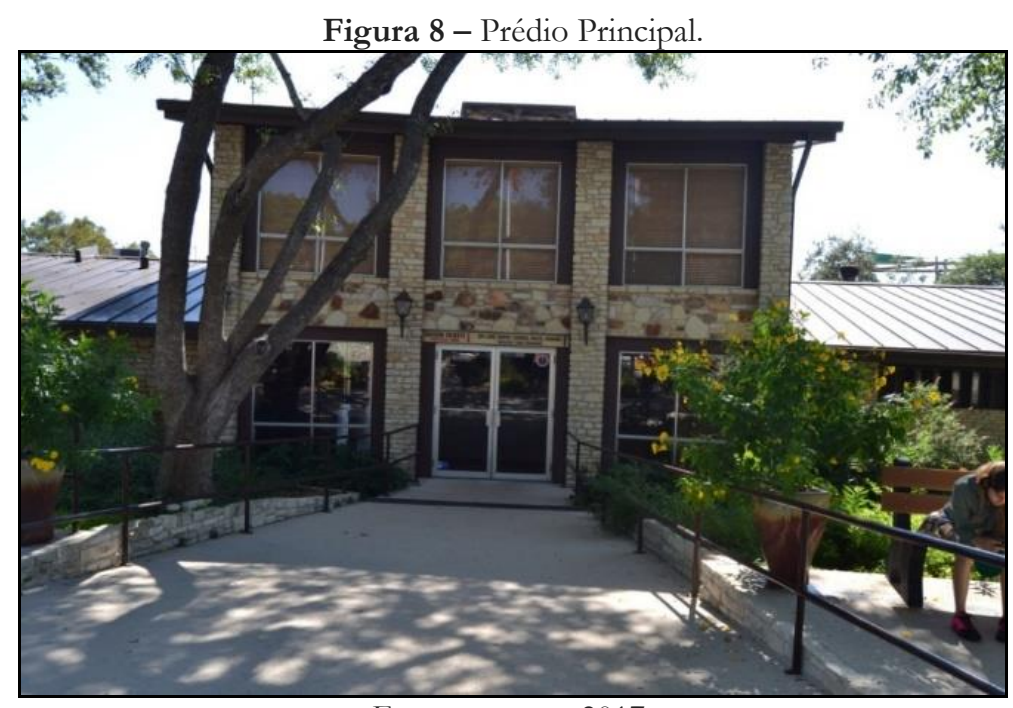

Fonte: o autor, 2017.

Os caminhos que são percorridos dentro do parque possuem corrimãos, para que as pessoas que tenham dificuldade de andar sintam-se mais seguras, bem como piso antiderrapante, com o objetivo de prevenir ou minimizar as quedas (Figuras 9 e 10).

Figura 9 - Rampa adaptada a pessoas com deficência, com corrimão e piso antiderrapante.

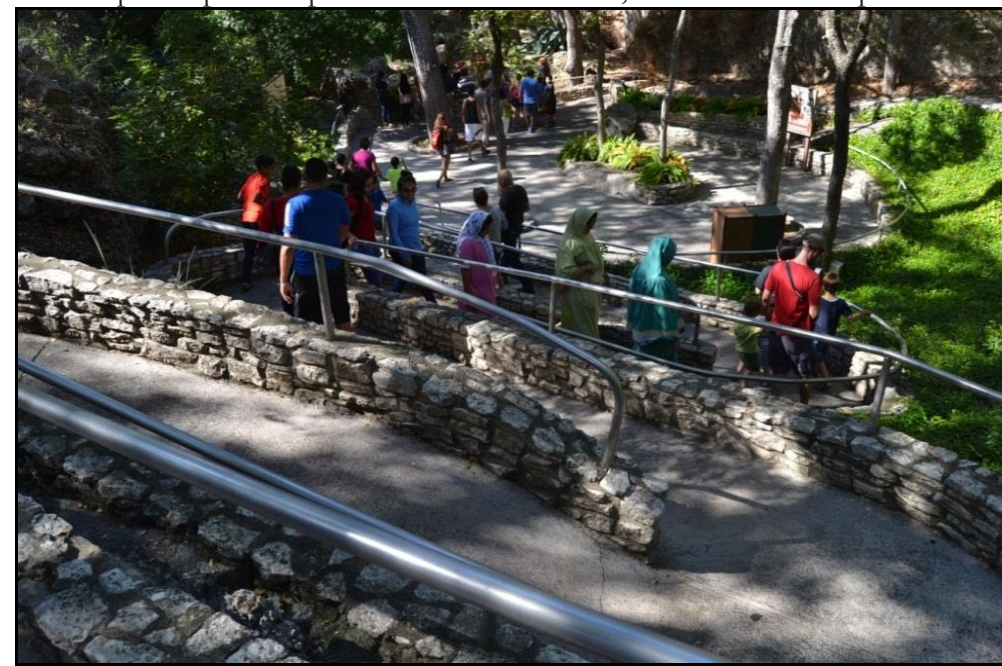

Fonte: o autor, 2017. 
Figura 10 - Rampas adaptadas a pessoas com deficiência física dentro da caverna, com corrimão e piso

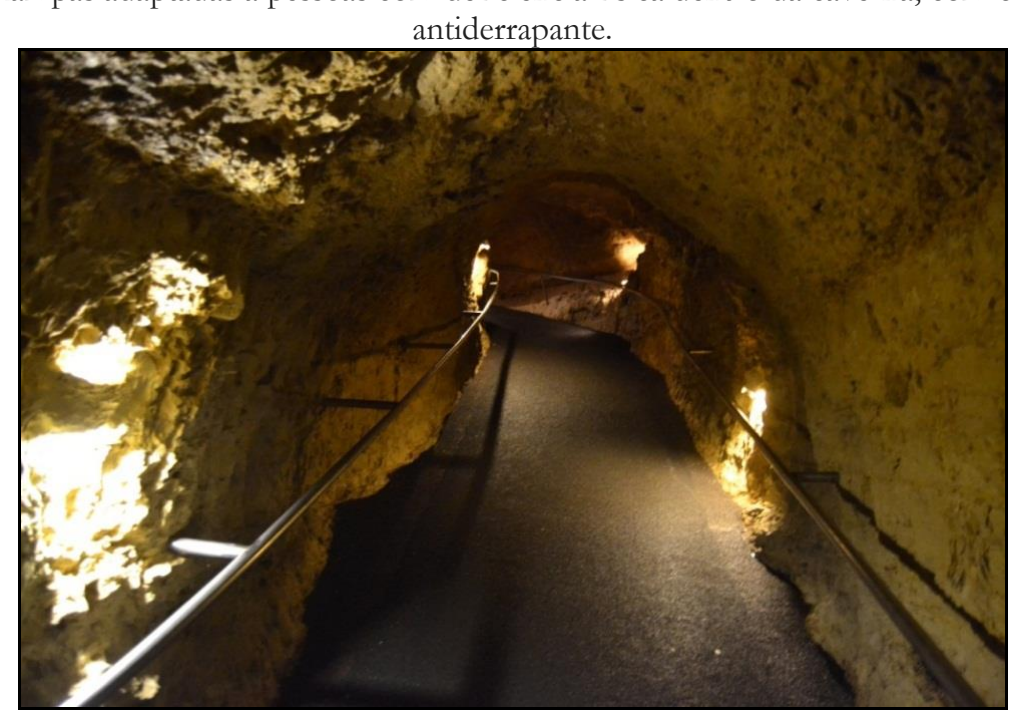

Fonte: o autor, 2017.

\section{CONSIDERAÇÕES FINAIS}

O Natural Brigde Caverns é um parque que possui uma grande área, que é muito bem explorada. Com várias atrações e atividades ao ar livre para os turistas, consegue despertar o interesse das pessoas de todas as idades, fazendo com que os visitantes aproveitem todo o dia no parque. Desde a chegada no parque, o turista é conscientizado sobre a importância da preservação da natureza eda interação homem-meio ambiente.

Com uma infraestrutura completa, contando com restaurante, banheiros limpos, guias experientes, passarelas com corrimão e piso antiderrapante, o parque oferece condições dos visitantes passarem todo o dia, podendo apreciar a natureza, realizar exercícios físicos e aprenderem sobre a geoconservação.

O sistema organizacional do Natural Bridge Caverns e as atividades geoturísticas podem servir de modelo para parques brasileiros que possuem cavernas e utilizem todo o seu potencial geoturístico de forma sustentável, gerando receitas e colocando os visitantes perto das belezas naturais do Brasil.

\section{REFERÊNCIAS}

BELLI FILHO, P. Geoconservação, geoturismo e geoparques. Florianópolis: Centro Tecnológico, Departamento de Engenharia Sanitária e Ambiental - UFSC, 2014. 53 p.

BENTO, L. C. M.; RODRIGUES, S. C. O geoturismo como instrumento em prol da divulgação, valorização e conservação do patrimônio natural abiótico - uma reflexão teórica. Pesquisas em Turismo e Paisagens Cársticas, Campinas, v. 3, n. 2, p. 55-65, 2010. 
BORGES, F. A. C.; TRAVASSOS, L. E. P.; GUIMARÃES, F. A. Proposta de criação de trilhas geoturísticas no Monumento Natural Estadual Gruta Rei do Mato (MNGRM), Sete Lagoas, Minas Gerais. CLIMEP - Climatologia e Estudos da Paisagem, Rio Claro, v. 8, n. 1, 2013.

DOWLING, Ross K. Global Geotourism - an emerging form of sustainable tourism. Czech Journal of Tourism, v. 2, n. 2, p. 59-79, dez. 2013.

EVANGELISTA, V. K.; TRAVASSOS, L. E. P. Estratégias para o geoturismo e geoconservação no Parque Estadual do Sumidouro, Minas Gerais. Brazilian Geographical Journal: Geosciences and Humanities research medium, ItuiutabaMG, v. 6, n. 2, p. 67-79, 2015.

GEOPARK AROUCA. Declaração de Arouca. Portugal, 12 de novembro de 2011.

Disponível em:

<http://www.azoresgeopark.com/media/docs/declaracao de arouca geoturismo.pdf $>$.

Acesso em: 19 maio 2018.

NATURAL BRIDGE CAVERNS. Disponível em: < https://naturalbridgecaverns.com $>$. Acesso em: 25 maio 2018.

JORGE, M. C. O.; GUERRA, A. J. T. Geodiversidade, Geoturismo e Geoconservação: Conceitos, Teorias e Métodos. Espaço Aberto, PPGG - UFRJ, v. 6, n. 1, p. 151-174, 2016.

LOPES, L. S. O.; ARAUJO, J. L.; CASTRO, A. J. F. Geoturismo: Estratégia de Geoconservação e de Desenvolvimento Local. Caderno de Geografia, v.21, n.35. Belo Horizonte: 2011.

MANTESSO-NETO, V. Geodiversidade, Geoconservação, Geoturismo, Patrimônio Geológico, Geoparque: novos conceitos nas geociências do século XXI. In: CONGRESO URUGUAYO DE GEOLOGIA, 6., 2010, Montevideo. Anais... Montevideo: 2010.

OFFICIAL TEXAS HISTORICAL MARKER COMAL COUNTY. Natural Bridge Caverns. Southwell Historical Foundation, 1967. 